\title{
ASEAN WAY DALAM PERPEKTIF HUKUM INTERNASIONAL
}

\author{
Sefriani \\ Fakultas Hukum Universitas Islam Indonesia \\ e-mail: sefri_ani@yahoo.com
}

\begin{abstract}
ASEAN is not free from conflict among its members. For the example is Conflict between gunmen called themselves as representative of Sulu Kingdom with Malaysian policeman, conflict territory surrounding preh vihear temple between Cambodia and Thailand, conflict ambalat between Indonesia-malaysia potentially disturb peace and security of regional. Nothing done by ASEAN as organization which is most responsible to peace and stability at South East Asia Region. This matter caused by ASEAN way followed by ASEAN as conflict Resolution. ASEAN Way claim ASEAN applied non intervention to domestic affair of its member. ASEAN way claim also unanimous vote in decision making. ASEAN way often make ACEAN became contra productive toward existence of ASEAN itself. Constructive intervention or flexible engagement or enhanced interaction is solution offered to enhance ASEAN more advantage for South East Asia Region.
\end{abstract}

Key words: ASEAN way, non intervention, constructive intervention

\begin{abstract}
Abstrak
ASEAN tidaklah bebas dari konflik antar anggotanya. Sebut saja beberapa waktu yang lalu konflik antara Sekelompok orang bersenjata yag menamakan dirinya perwakilan kerajaan Sulu dengan Pasukan Polisi Diraja Malaysia; konflik perbatasan di sekitar kuil preh vihear antara Kamboja dengan Thailand; Konflik kawasan ambalat antara Indonesia-Malaysia dan lain-lain yang berpotensi mengganggu perdamaian dan keamanan regional. Tidak ada upaya sedikitpun yang dilakukan ASeAN sebagai organisasi yang paling bertanggung jawab terhadap perdamaian keamanan kawasan asia Tenggara. Hal ini diakibatkan oleh ASeAN Way yang merupakan mekanisme penyelesaian snegketa yang dianut oleh ASeAN yang menuntut ASeAN bersikap non intervensi terhadap urusan dalam negeri anggotanya. ASeAN Way juga menuntut pengambilan suara berdasarkan mufakat. Apa yang dianut ASeAN ini terkadang menjadi kontraproduktif terhadap keberadaan ASeAN. Constructive intervention atau yang disebut juga dengan flexible engagement, atau enhanced interaction merupakan solusi yang ditawarkan untuk mendorong agar keberadaan ASeAN menjadi lebih berarti bagi kawasan
\end{abstract}

Kata kunci: ASeAN Way, Non intervensi, Constructive intervention

\section{A. Pendahuluan}

ASEAN tidaklah bebas konflik. Sebut saja konflik bersenjata antara tentara Malaysia melawan warga Philipina yang mengaku sebagai warga kerajaan Sulu, Mindanau, Philipina, di awal 2013 yang lalu yang mengklaim Sabah adalah wilayah milik leluhur mereka (http:// sorot.news. viva.co.id/news/read/396304-akarperang-sulu-malaysia, 22 Maret 2013) Jumlah korban yang tewas dari kedua belah pihak akibat konflik bersenjata antara pasukan tentara Malaysia melawan warga Sulu itu tidaklah sedikit. Malaysia menggunakan jet tempur dan senjatasenjata militrenya untuk menumpas warga Sulu, sehingga mengundang reaksi internasional termasuk Perserikatan Bangsa-Bangsa (PBB) yang menyerukan para pihak untuk menghentikan konflik bersenjata tersebut ( news.liputan6.com/ $\mathrm{read} / 527343 /$ konflik-sabah-malaysia-kerahkanjet-tempur-hadang-pasukan-sulu)

Konflik lain yang juga cukup menyita perhatian dan berpotensi mengancam perdamaian keamanan regional atau internasional adalah sengketa perbatasan di sekitar kuil Preh Viheaar dan sengketa kawasan Ambalat antara IndonesiaMalaysia. Konflik-konflik ini menampakan bahwa ASeAN hanya bersikap pasif sebagai organisasi di mana kekerasan, pelanggaran HAM, konflik berdarah, konflik bersenjata terjadi. PBB langsung bereaksi dengan menyerukan perdamaian, mengapa ASeAN hanya bersikap diam, seolah tidak terjadi apapun di wilayahnya. Sikap yang sama ditunjukkan oleh organisasi ini dalam kasus kekerasan terhadap etnis Rohingnya di Thailand, konflik perbatasan antara Kamboja dengan Thailand, konflik beberapa negara ASeAN di 
kawasan Spratly, konflik bersenjata yang telah terjadi bertahun-tahun antara Thailand melawan Malaysia di perbatasan tiga provinsi Thailand Selatan-Pattani, yala, dan Narathiwat-yang berbatasan langsung dengan Malaysia. Bahkan awal Maret lalu, konflik memanas, bom meledak menewaskan enam orang. (http://internasional. kompas.com/read/2013/03/16/02473056/Sabah. Konflik.dan.Belenggu.ASEAN,)

Sangat ironis pula, dalam kasus pemberontak Moro melawan pemerintah Philipina, bukan ASeAN yang tampil sebagai mediator antara kedua pihak yang bertikai tetapi justru Organisasi Konferensi islam (OKI). Kondisi yang berbeda ditunjukkan oleh organisasi-organisasi regional yang lain, dimana permasalahan di kawasan akan diselesaikan melalui organisasi regional dulu daripada melibatkan kekuatan di luar kawasan. Para ahli hukum organisasi internasional juga sepakat bahwa organisasi regional seharusnya merupakan organisasi yang paling tepat untuk menyelesaikan konflik yang terjadi di kawasannya. Organisasi regional dipandang lebih bisa memahami kondisi dan situasi yang ada di wilayahnya dibanding organisasi lain. Pasal 52 (1) Piagam PBB juga menegaskan bahwa

Nothing in the present charter precludes the existence of regional arrangements or agencies for dealing with such matters relating to the maintenance of international peace and security as are appropriate for regional action provided that such arrangements or agencies and their activities are consistent with the Purposes and Principles of the United Nations.

Dengan demikian sesungguhnya ASeAN bisa bertindak lebih banyak untuk menjaga stabilitas, keamanan, dan perdamaian di kawasan Asia Tenggara. Dengan sikap diamnya tak heran jika banyak pihak yang meragukan apakah ASeAN itu benar ada? Apa guna ASeAN bagi bangsabangsa Asia Tenggara? (Simon Chesterman:2012 :203). Pernyataan-pernyataan tersebut sangat wajar karena memang selama ini ASeAN seperti tidak ada dikala wilayah Asia tenggara dilanda konflik, kekerasan, atau pelanggaran HAM yang mengarah pada gangguan terhadap stabilita, keamanan dan perdamaian kawasan Asia Tenggara. Menjadi suatu pertanyaan besar tentunya konflik-konflik atau tindak kekerasan yang terjadi di wilayah Asia Tenggara. Berdasarkan uraian di atas, maka rumusan masalah dalam tulisan ini adalah (1) mengapa ASEAN senantiasa bersikap pasif terhadap konflikkonflik yang terjadi di kawasan asia tenggara ?. (2) apakah ASeAN way sebagai cara bagi ASeAN untuk menyelesaiakan masalah yang terjadi dalam tubuh ASeAN memerlukan reformasi ?

\section{B. Metode Penelitian}

Penelitian ini merupakan penelitian hukum normatif yang menggunakan data sekunder yang terdiri dari bahan hukum primer, sekunder dan tersier. Bahan hukum primer dalam penelitian ini adalah Deklarasi bangkok 1967, Treaty of Amity and cooperation in South East Asian Nations (TAC) 1976. Piagam ASeAN 2008 dan Piagam PBB 1945. Bahan hukum sekunder berupa hasil penelitian, tulisan dan pendapat para pakar hukum internasional terkait ASeAN dan prinsip non intervensi. Adapun bahan tersier berupa kamus dan ensiklopedi. Bahan-bahan hukum tersebut diperoleh dengan library research. Semua bahan hukum yang diperoleh dalam penelitian akan dikumpulkan, dikelompokkan sesuai variabel masing-masing, untuk selanjutnya dianalisis secara kualitatif. dengan menggunakan beberapa pendekatan. Beberapa pendekatan yang digunakan dalam penelitian ini adalah pendekatan perundang-undangan (statute approach), pendekatan historis, pendekatan konsep (conceptual approach), serta pendekatan perbandingan (comparative approach). (Peter Mahmud Marzuki :2005:93-95) Hasil dari penelitian ini akan disajikan dalam bentuk deskriptif analitis.

\section{Hasil Penelitian dan Pembahasan}

1. ASEAN Way Sebagai Cara ASEAN Menghadapi Berbagai Masalah dan Konflik

Terbentuk dari sebuah deklarasi tahun 1967, awalnya ASeAN adalah organisasi regional yang berusaha berintegrasi dalam sebuah institusi yang berdasarkan pada kerjasama fungsional. Oleh karananya ASe AN kemudian menjadi organisasi regional nonpolitik yang berfungsi dalam sektor-sektor ekonomi, teknik, keilmuan, sosial dan kebudayaan. Ide utamanya adalah bagaimana membuat suatu institusi regional tanpa mengancam kedaulatan nasional negara anggotanya namun tetap menguntungkan.(http://skiasyik.wordpress. com/2008/03/25/asean-charter/). Hal ini dikarenakan kondisi saat itu mayoritas anggota ASeAN adalah negara yag baru saja memperoleh kemerdekaan, konfrontasi Indonesia Malaysia baru saja berakhir, konflik Indocina dan kawasan Asia tenggara lainnya yang menjadi perebutan pengaruh dari negara-negara besar. Singkat kata 
kawasan asia tenggara saat itu penuh dengan percaturan politik dan kekuatan, sehingga kecurigaan antara masing-masing anggota masih ada (Syahmin A.K:1988: . 210-211).

Misi yang akan dicapai oleh ASeAN sesuai yang dinyatakan dalam Deklarasi Bangkok 1967 adalah untuk menciptakan kawasan Asia tenggara dalam suasana penuh rasa persahabatan, kedamaian dan kemakmuran. Negara-negara ASeAN harus mengusahakan kemajuan dalam perekonomian dan pembangunan dalam semua sektor yang ada, meningkatkan pertahanan keamanan nasional dan regional, serta menjaga kestabilan politik nasional maupun regional (Deklarasi Bangkok 1967).

Pada tahun 1976, dalam KTT ASeAN di Denpasar, Bali, bidang kerjasama ASeAN diperluas dengan bidang politik sebagaimana dinyatakan dalam Treaty of Amity and cooperation in South East Asian Nations (TAC). Hal penting yang dapat dicatat dari instrumen ini adalah bahwa segala sengketa yang timbul antar anggota ASeAN diusahakan penyelesaiannya secara damai. Intervensi atau ikut urusan dalam negeri negara anggota dan penggunaan kekerasan harus dihindarkan. Pasal 2 TAC menegaskan bahwa hubungan antar anggota ASeAN dilandasi prnsip-prinsip sebagai berikut.

a. Mutual respect for the independence, sovereignty, equality, territorial integrity and national identity of all nations;

b. The right of every State to lead its national existence free from external interference, subversion or coersion;

c. Non-interference in the internal affairs of one another;

d. Settlement of differences or disputes by peaceful means;

e. Renunciation of the threat or use of force;

f. effective cooperation among themselves.

Dari apa yang diatur dalam instrumen regional di atas nampak bahwa prinsip non intervensi menjadi prinsip utama yang melandasi kerjasama negara-negara anggota ASeAN. Prinsip nonintervensi sampai saat ini masih dipegang teguh oleh para anggota ASeAN dalam kebijakan regionalnya, di samping prinsip-prinsip lain seperti saling menghormati, konsensus, dialog dan konsultasi. (Hiro Katsumata:2004:237)

Mekanisme kerjasama dan penyelesaian konflik di kawasan Asia Tenggara yang dilandasi prinsip non intervency diplomacy, saling menghormati, konsensus, dialog dan konsultasi, juga larangan penggunaan kekerasan bersenjata itu disebut sebagai ASeAN Way (Joel Vander Kooi: 2007:19). Ditambahkan pula oleh Narine bahwa ASEAN way mengutamakan pengaturan dan implementasi nasional dibandingkan penciptaan otoritas supranasional (Shaun Narine,:2002:12-13). Nikolas Busse sebagaimana dikutip oleh Gillian Goh, menyatakan bahwa ASEAN way adalah metode dan norma yang digunakan oleh organisasi ASeAN dalam menghadapi situasi konflik di Asia Tenggara (Goh, GilliaN: 2013:115). Mekanisme tersebut disebut dengan ASeAN Way karena memang ASeAN memiliki cara dan gaya tersendiri dalam menangani permasalahan-permasalahan yang terjadi dalam kawasannya ( Joel Vander Kooi: 2007:19).

Pada tahun 1971 ASeAN way yang ditetapkan dalam TAC kembali ditegaskan oleh ASeAN. Pada tahun ini ASeAN menyatakan diri sebagai wilayah damai, bebas, dan netral. ASeAN merupakan The Zone of Peace, Freedom, and Neutrality (ZOPFAN). Kebebasan dalam ZOPFAN dimaksudkan sebagai kebebasan yang berhak diperoleh oleh setiap anggota untuk tidak diintervensi mengenai permasalahan domestik mereka. Intervensi disini bisa diartikan dalam hal kemerdekaan atau independensi serta integritas negara itu sendiri. Intervensi akan mengganggu kebebasan, kemerdekaan dan integritas ASeAN yang menginginkan netralitas di regionalnya. (Robin. Ramcharan, 2000:69)

ASeAN Way semakin memperoleh kekuatan ketika dinyatakan lagi dalam ASeAN Charter. Piagam ASeAN menyebutkan bahwa ASeAN dilandasi prunsip-prinsip utama sebagai berikut:

a. menghormati kemerdekaan, kedaulatan, kesetaraan, integritas wilayah, dan identitas nasional seluruh negara anggota ASeAN;

b. tidak campur tangan urusan dalam negeri negara anggota ASeAN;

c. penghormatan terhadap hak setiap negara anggota untuk menjaga eksistensi nasionalnya bebas dari campur tangan eksternal, subversi, dan paksaan;

d. menghormati kebebasan fundamental pemajuan dan perlindungan HAM, dan pemajuan keadilan sosial; 
e. menjunjung tinggi piagam PBB dan hukum internasional termasuk hukum humaniter yang telah disetujui oleh negara anggota ASeAN;

f. tidak turut serta dalam kebijakan atau kegiatan apapun termasuk penggunaan wilayahnya, yang dilakukan negara anggota atau nonanggota ASe AN atau subyek negara manapun yang mengancam kedaulatan, integritas wilayah, atau stabilitas politik dan ekonomi negara-negara anggota ASeAN ( Piagam ASeAN:2008).

Di samping prinsip-prinsip di atas, ASeAN Way juga dirumuskan dalam Pasal 2 (e) Piagam ASeAN yang menetapkan bahwa kerjasama negara-negara anggota ASeAN dilandasi prinsip non intervensi urusan dalam negeri anggotanya.

Dari sisi fungsional, ada empat kewajiban yang harus dipatuhi setiap negara anggota ASeAN sebagai konsekuensi dari keberadaan prinsip non intervensi, yaitu:

a. Pantangan untuk mengkritisi tindakan apapun dari satu negara anggota terhadap warga negaranya, termasuk pelanggaran terhadap hak-hak asasi manusia, serta membuat keputusan mengenai keanggotaan suatu negara berdasarkan sistem atau bentuk pemerintahannya;

b. Mengkritisi tindakan dari satu negara yang melanggar prinsip nonintervensi

c. Menolak pengakuan (recognition), permohonan suaka, ataupun bentuk dukungan lainnya terhadap kelompok pemberontak yang mengganggu kestabilan nasional negara tetangga

d. Menyediakan dukungan politis dan bantuan materi untuk negara yang sedang berkampanye menentang kegiatan-kegiatan subversif yang mengganggu stabilitas negara (Amitav Acharya:2001:58).

Lebih lanjut, Pasal 20 (1) ASeAN Charter menekankan bahwa pengambilan keputusan berdasarkan prinsip konsultasi dan konsensus. Satu catatan penting yang merupakan perkembangan baru dalam ASeAN Way tercantum dalam Pasal 21. Pasal ini menyatakan bahwa apabila berkaitan dengan implementasi komitmen di bidang ekonomi maka Pasal 21 (2) memungkinkan diterapkannya ketentuan yang lebih fleksibel termasuk formula minus MR X, apabila ada kesepakatan untuk melakukannya
(Joel Vander Kooi: 2007:19) ). Apa yang ditetapkan dalam Pasal 21 ini sesungguhnya merupakan penegasan dari Enhanced Dispute Settlement Mechanism (EDSM) yang dideklarasikan oleh ASeAN pada tahun 2004, yang merasakan tidak adanya jaminan atau lemahnya pelaksanaan komitmen kerjasama bidang ekonomi akibat kuatnya prinsip kedaulatan negara di organisasi mereka. (Joel Vander Kooi: 2007:1). Namun demikian ini hanya berlaku untuk bidang ekonomi saja, tidak untuk bidang yang lain seperti terjadinya kekerasan atau pelanggaran HAM di suatu negara ASeAN, termasuk kekerasan yang dilakukan aparat Malaysia terhadap penyusup dari Sulu.

Dari paparan di atas jelaslah bahwa sikap diam ASeAN dalam kasus Sabah merupakan bentuk pelaksanaan ASeAN Way, memberikan penghormatan kepada Malaysia untuk mengamankan integritas wilayahnya dari warga kerajaan Sulu yang menyusup masuk ke wilayah itu. Berdasarkan ASeAN Way, negara-negara anggota ASeAN berkomitmen untuk tidak mengakui, tidak melindungi, memberi bantuan kepada segenap kelompok yang mengancam stabilitas keamanan dan integritas wilayah anggota ASeAN seperti halnya yang dilakukan warga Sulu di sabah. Dengan konsep ASeAN Way, negara-negara ASeAN akan menganggap masalah Sabah adalah urusan dalam negeri Malaysia, sehingga tidak ingin ikut campur di dalamnya. Penghormatan terhadap apa yang dianggap menjadi urusan dalam negeri negara anggota lain secara tidak langsung ikut mencegah terjadinya salah persepsi dan kecurigaan antar anggota. Dengan ASeAN Way pula pantang bagi negara anggota ASeAN untuk mengkritisi tindakan apapun termasuk kekerasan yang dilakukan aparat Malysia terhadap penyusup Sulu di Sabah.

\section{ASEAN Way Memerlukan Reformasi}

Sekilas tidak ada yang salah dengan ASeAN Way. Prinsip non intervensi yang menjadi salah satu landasan kerja ASeAN merupakan prinsip yang berasal dari hukum internasional. Prinsip non intervensi adalah prinsip yang menyatakan bahwa suatu negara tidak memiliki hak untuk mencampuri (to interfere) urusan atau pemasalahan dalam negeri negara lain secara diktaktor. Prinsip ini merupakan satu dari lima prinsip peaceful coexistence yang tercantum dalam Piagam PBB yang kemudian diadopsi oleh 
para pendiri ASeAN dengan penyesuaian tertentu terhadap norma-norma regional. Bila ditarik jauh ke dalam, prinsip ini mengandung nilai-nilai penghormatan terhadap kedaulatan dan integritas teritorial dari setiap negara, penyelesaian setiap masalah politik melalui perundingan, serta peningkatan kerjasama dalam aspek keamanan dan pertahanan wilayah sesuai dengan salah satu tujuan pembentukan ASeAN, yaitu to promote peace in the region (Bambang Cipto:2007:26).

Kuatnya prinsip nonintervensi di kalangan anggota ASeAN dapat dimaklumi bila melihat sejarah bahwa hampir semua negara anggota ASeAN pernah mengalami menjadi bangsa jajahan. Pengalaman pahit sebagai bangsa jajahan yang tidak memiliki kedaulatan untuk mengatur bangsanya sendiri sangat mempengaruhi pola pikir para anggota ASeAN. Pada umumnya negaranegara ini ingin mendapatkan kemerdekaan, penghormatan terhadap kedaulatan secara mutlak melalui persamaan kedudukan sesama negara merdeka. Negara-negara bekas jajahan yang telah merasakan penderitaan dari pelaksanaan hak ekstrateritorial secara illegal yang dilakukan bangsa barat tidak akan mentolerir segala bentuk penundukan terhadadap negara mereka yang dilakukan oleh negara lain. (Dahai, qi, 2008:320)

Hal yang membedakan prinsip non intervensi yang dianut dan diatur dalam instrumen-instrumen hukum ASeAN dengan yang ada dalam piagam PBB adalah bahwa apa yang dianut ASeAN bersifat absolut. Tidak memberi perkecualian terhadap penerapan prinsip tersebut sebagaimana yang ditemukan dalam BAB VII Piagam PBB yang memberi kemungkinan diabaikannya prinsip nonintervensi apabila menurut Dewan keamanan PBB telah terjadi ancaman terhadap perdamaian dan keamanan internasional, pelanggaran perdamaian dan keamanan atau juga telah terjadi tindakan agresi. Praktek masyarakat internasional juga mengenal adanya humantarian intervention, intervensi atas dasar kemanusiaan. Ketika terjadi masalah kemanusiaan, humanitarian catastrope, yang menggoncang perasaan kemanusiaan, intervensi dalam bentuk penggunaan kekerasan dapat dilakukan dengan otoritas Dewan Keamanan PBB untuk menyelamatkan para korban dan mengakhiri krisis kemanusiaan yang terjadi di suatu negara manapun.. Tidak ditemukan aturan pengeculain dari prinsip non intervensi sebagaimana yang diatur dalam BAB VII Piagam PBB di atas dalam Piagam ASeAN. Tidak berlebihan kiranya apabila dikatakan ASeAN masih menganut prinsip non intervensi secara kolot, membabi buta.

Tidak ada yang salah juga dengan prinsip konsensus yang dianut ASeAN, karena prinsip ini juga dianut oleh PBB dan organisasi-organisasi internasional yang lain. Hal yang membedakan dengan yang dianut ASeAN adalah bahwa dalam aturan dan praktek organisasi internasional yang lain memungkinkan adanya voting bila konsensus tidak diperoleh. Konsensus atau kesepakatan bulat bukanlah harga mati sebagaimana yang dianut ASeAN. Prinsip suara mayoritas atau mayoritas bersyarat bisa diterapkan apabila kesepakatan bulat tidak dapat diperoleh. Adapun di ASeAN hal itu dimungkinkan hanya untuk bidang ekonomi seperti yang diatur dalam Pasal 21 (2) dengan formula minus Mr X-nya.

Di satu sisi diakui bahwa sesungguhnya prinsip non-intervensi juga konsensus yang selama ini dijunjung tinggi oleh ASeAN telah banyak berkontribusi terhadap eksistensi ASeAN. Jaminan pengakuan kedaulatan ini menjadi faktor penting untuk meredam sikap saling curiga sesama negara anggota. Hilangnya rasa saling curiga akan membantu tumbuhnya saling percaya yang cukup tinggi antara anggota ASeAN. Hal ini penting, sebab rasa percaya timbal balik menjadi prasyarat eksisnya suatu organisasi regional yang beranggotakan negara dengan perbedaan kepentingan yang tidak dapat terelakkan.

Prinsip nonintervensi dan konsensus yang merupakan isi dari ASeAN Way ini juga telah berfungsi sebagai mekanisme preventif terhadap munculnya sejumlah konflik terbuka di antara negara anggota ASeAN. Asean Way telah memberikan sumbangan yang teramat berarti dalam pengembangan ASeAN sejak berdirinya hingga saat ini.

Di sisi lain, seiring dengan kompleknya permasalahan yang dihadapi ASeAN, seiring dengan perkembangan hukum internasional yang ada, prinsip non inetrvensi dan konsensus yang absolut dan kaku yang dianut ASeAN dapat menjadi bumerang bagi ASeAN sendiri. ASeAN sering dianggap hanya merupakan asosiasi regional yang tidak responsif. memunculkan kekhawatiran akan hilangnya kepercayaan masyarakat terhadap kemampuan dan kapabilitas 
ASeAN di wilayah Asia Tenggara, bahkan mempertanyakan apakah sesungguhnya ASeAN ada atau tidak. Prinsip non intervensi memang tidak boleh ditinggalkan begitu saja, tatapi penerapan yang kaku akan menjadikan prinsip ini menjadi tidak efektif terutama ketika ketika dihadapkan dengan konsep keamanan regional di mana interaksi antar negara maupun nonnegara tidak dapat dihindari;(http://putrinyaperwirafisip09.web.unair.ac.id/artikel_detail-64064Masyarakat $\% 20$ Budaya $\% 20$ dan $\% 20$ Politik\%20Asia\%20Tenggara ASeAN\%20 Way.html). Penerapan yang kaku justru menjadikan prinsip non intervensi sebagai penghambat kinerja ASeAN.

Penerapan prinsip nonintervensi yang kaku akan memaksa ASeAN berperan sebagai pihak yang pasif ketika sebenarnya dituntut untuk mengambil kebijakan yang responsif terhadap dinamika hubungan regional. Apalagi dengan kondisi dimana negaranegara anggota ASeAN belum sepenuhnya berada dalam skala keamanan yang stabil; dalam artian memiliki pemerintahan yang demokratis dan menjunjung hak asasi manusia seperti yang menjadi hegemoni dalam sistem internasional saat ini. Prinsip konsensus yang kaku juga akan menghambat kerja ASeAN. Bisa dibayangkan hanya karena ada satu negara saja yang tidak setuju, sementara sembilan yang lain setuju agar ASeAN melakukan sesuatu, terpaksa tindakan tersebut tidak bisa dilakukan untuk menghormati satu negara yang tidak setuju dan mememenuhi tuntutan konsensus.

Belajar dari tidak efektifnya penerapan prinsip nonintervensi dan konsensus yang kaku dalam ASeAN Way, oleh karenanya diusulkan adanya konsep alternatif seperti constructive intervention atau yang disebut juga dengan flexible engagement, atau enhanced interaction. Flexible engagement adalah perbincangan antar seluruh anggota ASeAN mengenai permasalahan serta kebijakan domestik tanpa bermaksud untuk mengintervensi. (Robin. Ramcharan, 2000:68)

Konsep Flexible engagement yang diusulkan Thailand awalnya tidak diterima oleh negara-negara anggota ASeAN, kecuali Filipina, karena menganggap proposal tersebut sebagai pelanggaran intervensi isu domestik suatu negara. Myanmar, Laos, Kamboja dan Malaysia menyebutkan keberatan dari segi historis yang sudah terlalu diintervensi oleh pihak eksternal sehingga mereka ingin menyelesaikan permasalahan sesuai dengan cara mereka sendiri (Robin. Ramcharan, 2000:79)

Perkembangan yang terjadi akhirnya menunjukkan bahwa fleksibilitasi dianggap perlu karena penerapan prinsip non-intervensi dan konsensus yang kolot, absolut, atau membabi buta menjadi tidak relevan lagi. Permasalahan yang semakin kompleks yang dihadapi negara-negara ASe AN juga perkembangan hukum internasional yang ada menuntut ASeAN dapat menyelesaikan tantangan-tantangan baru, seperti permasalahan HAM, lingkungan hidup, ekonomi, demokrasi, perbatasan, dan isu hubungan sosial yang lain yang yang membutuhkan respon multilateral, dengan cara yang lebih terbuka dan efisien. http://putrinyaperwira-fisip09.web.unair. ac.id/artikel_detail64064Masyarakat $\% 20$ Budaya $\% 20$ dan $\% 20$ Politik $\% 20$ Asia $\% 20$ Tenggara-ASeAN\%20Way.html

Konsep Flexible engagement kemudian dianggap mampu mengontrol anggota ASeAN (Jürgen. Haacke:1990. :583) Flexible engagement atau intervensi konstruktif memperbolehkan adanya intervensi terutama ketika permasalahan internal berpotensi mengganggu stabilitas regional, seperti permasalahan keamanan dan kemakmuran.

Sesungguhnya konsep flexible engagement atau constructive intervention yang diusulkan Thailand bukanlah hal baru. Piagam PBB yang telah dibuat sejak tahun 1945 telah mengenal semuanya itu. Meskipun PBB didirikan dengan berlandaskan prisip nonintervensi, namun prinsip ini tidak mutlak. Prinsip intervensi bisa dilanggar ketika menurut Dewan Keamanan telah terjadi ancaman perdamaian keamanan, pelanggaran perdamaian keamanan atau telah terjadi tindakan agresi. Dewan Keamanan dapat mengambil semua tindakan yang dianggap perlu untuk menghentikan tindakan yang mengancam perdamaian keamanan, melanggar perdamaian keamanan atau tindakan agresi. Perkembangan Hukum Internasional juga menunjukkan adanya humanitarian inetrvensi juga right to protect. Keduanya merupakan bentuk intervensi dengan penggunaan kekerasan dengan alasan kemanusiaan untuk melindungi korban-korban pelanggaran HAM yang masif.

Mengambil analogi di atas semestinya ASe AN Way juga mengadopsi prinsip nonintervention sebagaimana yang dianut 
PBB, tidak setengah-setengah. Dalam konteks Piagam ASeAN, maka seharusnya ASeAN summit dapat mengambil peran sebagaimana yang dilakukan Dewan keamanan PBB. Apabila menurut ASeAN Summit suatu masalah atau konflik yang terjadi di suatu negara sudah mengancam stabilitas, perdamaian dan keamanan kawasan Asia Tenggara, maka wajib hukumnya bagi ASeAN untuk merespon, mengambil tindakan untuk meminimalisir korban juga memulihkan situasi yang mengancam stabilitas, perdamaian dan keamanan kawasan ASeAN tersebut. Tidak hanya bersifat pasif. Konflik di Sabah misalnya sangat berpotensi mengancam stabilitas, keamanan, perdamaian di kawasan ASe AN mengingat Sabah berbatasan langsung dengan Indonesia dan Brunei Darussalam.

Dari fakta itu semua dapat disimpulkan bahwa keberadaan ASEAN way dalam menyelesaikan konflik di ASEAN tetaplah harus dipertahankan sebagai jati diri ASeAN. ASeAN tetap harus memiliki mekanisme sendiri dalam menjaga stabilitas keamanan kawasan Asia Tenggara agar tidak mudah didikte kekuatan-kekuatan luar yang justru bisa memperkeruh suasana. ASeAN-lah yang paling memahami kondisi negaranegara anggotanya. Ada beberapa hal yang perlu direformasi seperti penerapan prinsip nonintervensi dan konsensus yang sangat kaku atau absolut sebagaimana yang diberlakukan selama ini untuk menyesuaikan dengan kompleksitas masalah, juga kebutuhan dan perkembangan hukum internasional. Reformasi tersebut akan semakin menguatkan pondasi ASEAN way, akan menimbulkan kepercayaan antaranggota ASeAN sendiri sebagai kawan dan partner dalam hubungan regional juga kepercayaan pada masyarakat internasional secara umum bahwa ASeAN dengan ASeAN way-nya mampu dan memiliki kapabilitas untuk menjaga stabilitas, keamanan, perdamaian dan kesejahteraan anggotanya.

\section{d. Simpulan}

Sikap pasif ASeAN dalam dalam konflik bersenjata Sulu-Malaysia disebabkan oleh ASeAN Way yang dianut oleh ASeAN dalam menghadapi sengketa di kawasan Asia Tenggara. Keberadaan ASEAN way dalam menyelesaikan konflik di ASeAN tetaplah harus dipertahankan sebagai jati diri ASeAN. Namun demikian, ada beberapa hal yang perlu direformasi seperti penerapan prinsip non intervensi dan konsensus yang sangat kaku atau absolut sebagaimana yang diberlakukan selama ini untuk menyesuaikan dengan kompleksitas masalah, kebutuhan dan perkembangan hukum internasional. Reformasi tersebut akan semakin menguatkan pondasi ASEAN way, akan menimbulkan kepercayaan antar-anggota ASeAN sendiri sebagai kawan dan partner dalam hubungan regional juga kepercayaan pada masyarakat internasional secara umum bahwa ASeAN dengan ASeAN way-nya mampu dan memiliki kapabilitas untuk menjaga stabilitas, keamanan, perdamaian dan kesejahteraan anggotanya. 


\section{daftar Pustaka}

Acharya, Amitav. 2001. constructing a Security community in Southeast Asia: ASEAN and the Problem of Regional Order. London: Routledge.

Arfi Bambani Amri. "Akar Perang Sulu Malaysia, .Warisan konflik kolonial. Antara bayar sewa dan penyerahan.,". diakses [22 Maret 2013] di http://sorot.news.viva.co.id/news/read/396304-akarperang-sulu-malaysia,

Bambang Cipto. 2007. hubungan Internasional di Asia Tenggara: Teropong terhadap Dinamika, Realitas, dan Masa Depan. yogyakarta: Pustaka Pelajar.

Chesterman,Simon. 2012. "Does ASeAN exist? The Association of Southeast Asian Nations as an International Legal Person". dalam Singapore Year Book of International Law. 12 S. Y.B.I. L. 199, hlm 199-211

Goh, Gillian. The ASEAN Way: Non-Intervention and ASEAN's Role in Conflict Management, h/m.115. Diakses 17 maret 2013: http://www.stanford.edu/group/sjeaa/journal3/geasia1.pdf

Haacke, Jürgen. 1999. "The Concept of Flexible engagement and The Practice of enhanced Interaction: Intramural Challenges to The Asean Way". Dalam The Pacific Review, Vol 12, No. 4. London: Taylor \& Francis Ltd. HIm. . 281-611.

I Wayan Parthiana. 1987. Beberapa Masalah dalam hukum internasioanl dan hukum Nasional Indonesia. Bandung: Binacipta.

Katsumata. Hiro 2004. "Why Is Asean Diplomacy Changing? From "Non-Interference" to "Open and Frank Discussions", dalam Asian Survey, Vol. 44, No. 2, hlm 237. diakses di http://ezproxy.ugm. ac.id:2056/action/doBasicResults?hp=25\&la=\&gw=jtx\&jcpsi=1\&artsi=1\&query=asean\&sbq=ase an\&si=76\&jtxsi=76 19 Maret 2013

Kooi, Joel Vander 2007, "The ASeAN enhanced Dispute Settlemet Mechanism: Doing it the ASeAN Way". dalam New York International Law Review ,20 N.Y. Int'l L. Rev. 1, hlm. 1-37

Narine, Shaun 2002. Explaining ASEAN: Regionalism in southeast Asia, Lynne Rienner Publishers, Inc

qi, Dahai. 2008." State Immunity, China and Its Shifting Position", 7 Chinese J. Int'l L. 307. hlm.307-333

Ramcharan, Robin. 2000. "ASeAN and Non-interference : A Principle Maintained". dalam Contemporary Southeast Asia, Vol. 22, No.1, hlm.60-88

Syahmin A.K. 1988. Masalah-Masalah Aktual hukum Organisasi Internasional. Bandung: Armico.

"konlik sabah malaysia kerahkan jet tempur". diakses di news.liputan6.com/read/527343/konflik-sabahmalaysia-kerahkan-jet-tempur-hadang-pasukan-sulu. [21 maret 2013]

"Malaysia versus Kesultanan Sulu. Tipe Konflik Unik dalam Sistem Negara Bangsa', diakses di http:// hi.umy.ac.id/malaysia-vs-kesultanan-sulu-tipe-konflik-unik-dalam-sistem-negara-bangsa/

Sabah. Konflik, dan belengguASEAN. diakses di http://internasional.kompas.com/read/2013/03/16/02473056/ Sabah.Konflik.dan.Belenggu.ASEAN, [21 maret 2013]

http://skiasyik.wordpress.com/2008/03/25/asean-charter/ - _ftn1 diakses [19 maret 2013]

"ASeAN Way". diakses [22 Maret 2013] di http://putrinyaperwira-fisip09.web.unair.ac.id/artikel_ detail-64064 Masyarakat\%20Budaya\%20dan\%20Politik\%20Asia\%20Tenggara-ASeAN\%20Way. html 